УАK 343.9

ББК 67.51

DOI 10.22394/1682-2358-2021-4-52-60

D.A. Brekbov, post-graduate student of the Criminology Department, V.Ya. Kikot' Moscow University of the Ministry of Internal Affairs of the Russian Federation

\section{METHODS \\ OF COMMITTING \\ FRAUD USING \\ THE INTERNET, MOBILE \\ COMMUNICATIONS \\ AND REMOTE \\ BANKING SYSTEMS}

The article deals with the problems associated with the lack of a clear specification and a unified approach in the terminology used in the implementation of quantitative accounting and classification of new ways of committing crimes in the field of information technology. A typology of these crimes is proposed, which makes it possible to create a single mechanism for accounting and analytical operations in assessing the state and dynamics of cybercrime.

Key words and word-combinations: cybercrime, Internet fraud, information technology crime.
А.A. Брехов, адэюнкт кафедри криминологии Московского университета МВА России им. В.Я. Кикотя (email: 89266666634@mail.ru)

\section{СПОСОБЫ СОВЕРШЕНИЯ МОШЕННИЧЕСКИХ АЕЙСТВИЙ \\ С ИСПОАЬЗОВАНИЕМ СЕТИ «ИНТЕРНЕТ», СРЕАСТВ ПОАВИХКНОЙ СВЯЗИ И СИСТЕМ АИСТАНЦИОННОГО БАНКОВСКОГО ОБС УУЖИВАНИЯ}

Аннотация. Рассматриваются проблемы, связанные с отсутствием конкретизации и единого подхода в терминологии, применяемой при осуществлении количественного учета и классификации новых способов совершения преступлений в сфере информационных технологий. Предлагается типология этих преступлений, что дает возможность создать единый механизм учетноаналитических операций при оценке состояния и динамики киберпреступности.

Ключевые слова и словосочетания: киберпреступность, мошенничество в сети «Интернет», преступления в сфере информационных технологий.

B условиях постоянного роста преступлений в сфере информационных технологий на территории государств участников Содружкества Независимых Государств происходит консолидаџия 
усилий правоохранительных органов стран Содружества по ряду направлений международного взаимодействия [1] .

В связи с появлением новых способов совершения преступлений в сфере информационных технологий приходится констатировать, что принимаемых мер по противодействию этому виду криминаца явно недостаточно. Особенно остро обозначилась пробцема распространения вреАоносных компьютерных программ, преАставляющих угрозу государственным и транснациональным информационным ресурсам. Правоохранительные органы фиксируют активные попытки криминальных структур использовать открытые телекоммуникационные и ведомственные информационные сети дмя проведения крупных финансовых махинаций и мошеннических акций.

Особую тревогу правоохранительных органов стран Содружества вызывает практика использования информационных технологий террористическими организациями по поиску и вербовке граждан, манипуляции массовым сознанием и распространению экстремистских взгАЯАОв.

Основную Аолю компьютерных инцидентов составляет распространение вредоносных программ, предназначенных дмя хишения учетных записей пользователей Интернета, и преступления, связанные с электронными платежными системами. Способы совершения подобных преступлений обусловлены особенностями предмета и среАств их совершения, использованием в преступных целях установленного поряАка осуществления банковских операций по переводу безналичных денежных средств, находящихся на счетах банковских платежных карт, с использованием средств мобильной связи, а также порядка оказания ускуг подвижной (мобильной) связи операторами.

Мошеннические действия, в том числе с использованием мобильных средств связи, путем перевода денежных средств со счетов банковских карт потерпевших на счета третьих $и ц$ в большинстве случаев совершаются в отношении держателей банковских карт и подключенных к системам дистанционного банковского обслуживания.

Анализ материалов судебной практики позвоцяет кцассифицировать способы завладения чужими денежными средствами, находящимися на счетах банковских карт потерпевших.

Цифровая револющия принесла не только блага, новейшие технологии все активнее берет на вооружение и криминалитет: «ПосреАством Интернета совершаются хищения чужого имущества, ведется торговця наркотиками, оружием, АюАьми, распространяется экстремистская $\Lambda и-$ тература, вербуются новые чиены террористических группировок. СреАи новых угроз - мошенничества с использованием сотовой связи, а 
также средств IР-телефонии. Преступники научились подменять поА-

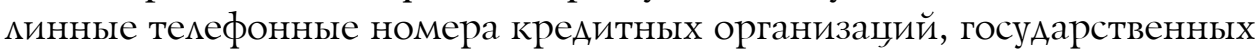
служб, выдавая себя за их работников. В прошлом году число противоправных деяний, совершенных с применением информационных технологий, увеличилось в Ава раза, в январе - сентябре текущего года - почти на 70\%» [2] .

За последние несколько цет многое сделано дия повышения результативности предупреждения и пресечения таких преступлений, сокращения возможкности использовать передовые технологии в незаконных цемях. Совершенствуется нормативная правовая база, в частности, ужесточена ответственность по отдельным видам IT-преступлений и административных правонарушений. В практическую деятельность внеАряются новые формы и методы противодействия им. Заключены соглашения об информационном взаимодействии в эмектронном виде между МВА России и государственными органами, а также рядом финансово-кредитных организаций на федеральном и региональном уровнях. Аیя качественного расследования уголовных дем этой категории создаются следственнооперативные группы из числа наиболее подготовленных сотрудников.

В 2020 и в начале 2021 г. в полтора-два раза выросло число раскрытых IT-преступлений и направленных в суд уголовных дел. В два раза больше установлено виновных миц. С 2018 г. в московском регионе заАержаны организованные группы, общей численностью почти тридцать человек, совершавших мошеннические действия в отношении пожимых граждан на территории пяти субъектов РФ. Используя мобильную связь, они преАставлялись сотрудниками банков, соџиальных служб и поА видом получения компенсации за покупку ранее приобретенных товаров ици мекарств похищали сбережения пенсионеров. Аоказана причастность фигурантов к 87 эпизодам [3].

В мае 2021 г. пресечена деятельность группы, управцявшей сетью медицинских клиник в ряде регионов России, в том числе в Москве и Санкт-Петербурге. ЗАоумышиенники через комл-центры приглашали пациентов, вводици их в забцуждение о наличии заболеваний, требующих неотложного Аорогостоящего мечения, и Аля оплаты фиктивных медицинских услуг склоняли к оформлению кредитов на суммы до полумимлиона рублей. Установлено более 11 тысяч потерпевших. По предварительным Аанным, общая сумма ущерба превышает мимлиарА рублей [3] .

Важной задачей сегодня является мониторинг, блокировка и удамение противоправного контента: «Во взаимодействии с Генеральной прокуратурой, Роскомнадзором, а также сайтов и страниц, через которые распространяются наркотики, детская порнография, требуется разработка механизмов оперативной блокировки и мошеннических комА-центров, фишинговых сайтов, интернет-пирамиА». 
1. Въедение потерпевиего в заблуждение относительно иелей перевода денежньх средств путем совершения ему телефонних звонков или напрабления СМС-сообщений.

Под воздействием заблужжения потерпевший самостоятельно производит перевод денежных средств со своего счета на счета третьих миц с использованием систем «Интернет-банкинг» и «Мобильный банкинг» через терминалы банков или иным способом.

1.1. Побуждение потерпевшего к совершению действий по перевоАу денежных среАств со своего счета на счета третьих $и ц ц$ путем сообщения ему по телефону или направлением СМС-сообщения цожных сведений о внезапно возникших у его близких родственников серьезных неприятностей и проблем, связанных с несчастными случаями, совершением дорожно-транспортного происшествия, причинением вреда здоровью третьих миц, задержанием за хранение наркотических среАств, совершением Аругих преступлений кибо с Аолговыми обязательствами, Аля незамедлительного решения которых срочно требуется определенная сумма денег.

При этом змоумышленники осуществляют звонки ици направцяют СМС-сообщения потерпевшим по случайно подобранным абонентским номерам телефонов, как мобильных, так и стационарных, представляются от имени их родственников, Арузей, знакомых или сотрудников правоохранительных органов, а также указывают абонентский номер телефона или номер банковской карты, на который следует осуществить перевод и сумму денежных средств, которую необходимо перечислить. Во многих случаях мошенничество Аанным способом совершают мица, отбывающие наказание в местах мишения свободы.

1.2. Уведомление потерпевшего по телефону (в основном путем рассымки СМС-сообщений) о выпавшем ему крупном призе при розыгрыше мотереи и необходимости перевода определенной суммы денежных средств на указанный номер телефона или платежного среАства в качестве налоговых или иных платежей как условия получения приза.

1.3. Направление потерпевшему посреАством СМС-сообщений можных уведомлений о зачислении на его банковский счет определенной суммы денег, а через некоторое время новых сообщений об ошибочном зачислении этих сумм с просьбой возврата их посредством перевоАа на указываемый номер телефона или банковской карты.

1.4. Осуществление звонков потерпевшим от имени оператора связи с предложением подкАючить новую услугу и набрать Аля этого поА Аиктовку опреАеленный коА, который в Аействительности является комбинацией дмя перевода денежных средств со счета абонента на счет третьего Аица. 
1.5. Сообщение потерпевшему заведомо можкных сведений посредством телефонных звонков или путем направления СМС-сообщений от имени банка о якобы возникших технических или иных проблемах, препятствующих Аальнейшему использованию им своей банковской карты с предложением совершить для устранения данных препятствий определенные операции по банковскому счету через системы «Интернет-банкинг», «Мобильный банкинг» или через терминал банка. Совершение потерпевшим, введенным в заблуждение, данных операций приводит в действительности к переводу денежных среАств со счета его банковской карты на счет третьего миџа.

Такие действия производятся миџами, совершающими мошенничество, как правило, двумя способами.

Первый способ: потерпевшему направляется можное уведомление посредством СМС-сообщения от имени банка о временной блокировке банковской карты с предложением навести справки по указанному в СМС-сообщении номеру телефона.

В скучаях, когда потерпевший, позвонив по данному номеру, пытается выяснить причину блокировки его банковской карты, циџо, совершающее мошенничество, преАставившись сотрудником службы безопасности банка, объясняет причины блокировки карты попытками посторонних миц получить информацию о реквизитах банковской кар-

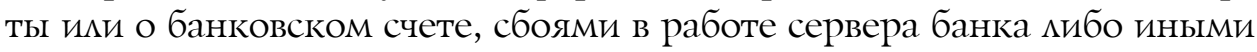
надуманными причинами.

Затем змоумышиенники, в зависимости от информации, предоставменной потерпевшим при ответах на поставленные вопросы, преАлагают совершить определенные действия посредством «Интернет-банкинга», «Мобимьного банкинга» мибо через ближайший банкомат. При этом потерпевшему сообщается о необходимости оперативного совершения данных действий, поскольку в противном случае якобы возникнет необходимость совершения операции замены карты, которая может затянуться на долгое время, в течение которого воспользоваться денежными средствами на карте будет невозможно.

В случае согласия потерпевшего на выполнение можной операции разблокировки карты он подходит к банкомату и, перезвонив по указанному ему номеру телефона, действуя под диктовку, вставляет свою банковскую карту в банкомат, набирает на нем коА доступа к карте и сообщает остаток денежных среАств на карте. Затем набирает поА Аиктовку цифры, якобы коА Аля разблокировки карты, а в действительности переводит денежные средства со своей карты на банковскую карту ици на цицевые счета абонентских номеров сотовых операторов

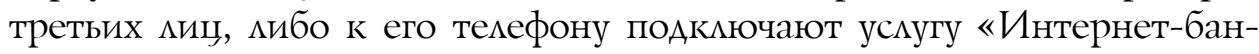


кинг» или услугу «Мобильный банк», позволяющую управцять счетом его банковской карты.

При этом потерпевшему становится известно по полученным чекам или поступающим СМС-уведомлениям об осуществлении им операции перевода денежных средств. ОАнако потерпевшего убеждают, что переведенные им денежные средства зарезервированы и в течение нескольких часов будут возвращены обратно на его счет и предлагают не пользоваться картой Ао их поступцения [4].

После этого миџа, совершающие мошенничество, переводят поступившие денежные средства на банковские счета Аругих киџ кибо на счета до востребования через системы денежных переводов, осуществляемых отдельными кредитными учрежкениями. При этом денежные средства в банке получают кица, неосведомленные об истинном их происхождении, за денежное вознаграждение и далее передают их незнакомым им мицам.

Используемые мошенниками Аля рассылки СМС-сообщений, разговоров с потерпевшими и дмя перечисления денежных средств абонентские номера операторов связи, как правило, оформляются ими на вымышленных миџ, а банковские карты, на которые перечисляются похищенные денежные средства, принадлежкат, как правило, не имею-

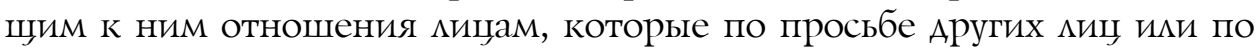
своей инициативе оформляют их на свое имя и передают за денежное вознаграждение малознакомым или вообще незнакомым мицам.

Второй способ: введение в заблуждение (в том числе с помощью методов социальной инженерии, то есть с использованием познаний в области психологии) держателя банковской карты (владельца счета) относительно сущности операций, Аля получения информации, необ-

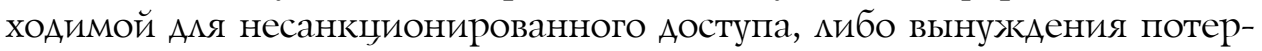
певшего совершить необходимые злоумышиеннику действия.

Аиџа, совершающие мошенничество, при первом телефонном разговоре с потерпевшим выясняют, что абонентский номер его телефона подключен к системе дистанционного банковского обслуживания. Поводом к образованию Аоверительных отношений с потерпевшим может стать, например, то, что преступник преАставляется сотрудником службы социамьного обеспечения мибо сотрудником банка, целью которого является перечисление дополнительной соџиальной выплаты и т.п.

Затем змоумышиенники предмагают потерпевшему посреАством Аанной системы совершить Амя разблокировки банковской карты операции якобы по временному резервированию денежных средств, нахоАящихся на его банковском счете, а в действительности по переводу их на счета третьих миџ. После этого потерпевший, введенный в заблуж- 
Аение, переводит под Аиктовку денежные средства со своего счета на указанный ему счет банковской карты или абонентский номер, будучи уверенным, что переведенные им денежные средства в течение суток поступят обратно на его банковский счет.

К разновидностям введения в заблужкение потерпевшего также следует отнести перевод среАств со счета потерпевшего посреАством использования системы «СМС-банкинга» - разновидности технологии Аистанционного банковского обслуживания с использованием СМС-сообщений, в которой доступ к банковским счетам и операциям по банковским счетам предоставляется в мюбое время с использованием номера мобильного телефона клиента, предварительно зарегистрированного в банке. Эта технология, помимо пассивного СМС-оповещения о проведенных операциях и состоянии счета, позволяет осуществлять «активное» СМС-оповещение - отправку CMC-сообщений в ответ на получаемые от клиента СМС-запросы, например, запрос баланса банковской карты или счета, мини-выписки ици блокировки банковской карты, а также отправлять банку через сеть оператора подвижной связи команды на проведение операций с денежными средствами клиента банка-владелыца сим-карты.

Аиџа, совершающие мошенничество, также используют способ совершения операций по USSD-запросам, когда обращаются к потерпевшему с просьбой набрать USSD-команду или отправить СMC на специализированный номер банка мля совершения перевода.

1.6. Вмешательство в функционирование средств хранения, обработки и передачи компьютерной информации и информационно- тецекоммуникационных сетей путем блокирования абонентского номера потерпевшего, восстановцения его на дубцикат сим-карты и перечисления денежных средств с банковского счета потерпевшего посредством системы «Мобицьного банкинга», перевод денежных средств с банков-

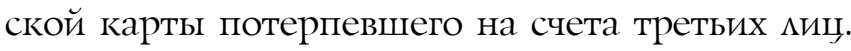

В некоторых случаях дмя получения Аубликата сим-карты, установменной в телефоне потерпевшего, мошенники могут вступать в сговор с преАставителями оператора связи, работающими в офисах продажк и обслуживания клиентов. В отдельных случаях Аанные преступления совершаются представителями оператора связи самостоятельно.

Особенностью указанных способов совершения мошенничества яв-

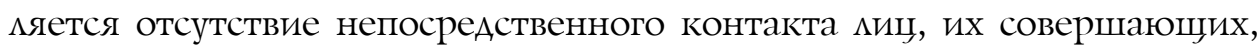
с потерпевшими, поскольку послеАние вводятся в заблуждение и побужАаются к совершению опреАеленных Аействий посреАством среАств Аистанционной коммуникации.

2. Использование найденного, похищенного, приобретенного либо случайно оказавиегося у субгекта преступления чужого телефонного 
аппарата с абонентским номером Владельца, подключенного к услуге «Мобильный банкинг».

Потерпевший, у которого телефонный аппарат по тем или иным причинам выбыл из владения (утерян, похищен, продан вместе с симкартой), своевременно не обращается в банк с просьбой отключить от

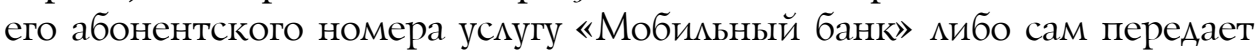
свой телефонный аппарат Аругому киџу Аля временного пользования или оставцяет его временно без присмотра. Аиџа, совершающие мошенничество, обнаружив при пользовании телефоном, что тот поАключен к указанной услуге, совершают хищение денежных средств, находящихся на банковском счете потерпевшего.

3. Использование подключенного к услуге "Мобильньй банкинг» абонентского номера, ранее принадлежабшего другому абоненту.

Аанный способ совершения мошенничества заключается в использовании кицами, его совершающими, того обстоятельства, что потерпевший, осуществив замену абонентского номера своего телефона, поАкАюченного к услуге «Мобильный банкинг», не предупредиц об этом кредитную организацию, а его абонентский номер впоследствии был перерегистрирован оператором связи на имя другого миџа. Обнаружив при пользовании телефоном с таким абонентским номером, что тот подкцючен к услуге «Мобильный банкинг», новый вмаделец номера производит посреАством указанной услуги перевод денежных среАств потерпевшего на свой банковский счет или на счета третьего мица.

Так, Н. быма осуждена за совершение преступлений, предусмотренных ч. 1 и 2 ст. 159.6 УК РФ «Мошенничество в сфере компьютерной информации». Согласно приговору суда Н., получив на мобильный те-

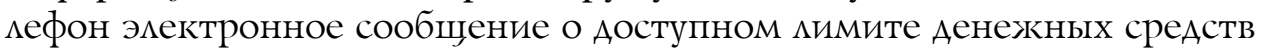
на не принадлежкашем ей банковском счете, открытом на имя Ш., имела умысел на хищение указанной суммы и, реализуя его, используя принадмежаший ей мобимьный телефон и сим-карту, к которой была ошибочно подключена услуга мобильного банка Сбербанка России, предоставцяющая техническую возможность распоряжаться денежными средствами, находящимися на расчетном счету Ш., путем ввода компьютерной информации в форме электрических сигналов (СМС-сообщения на номер 900) посреАством телекоммуникационной сети оператора сотовой связи похитила денежные средства, принамлежашие Ш. (приговор Грачевского районного суда Ставропольского края от 13 июня 2013 г. по уголовному делу № 1-82/2013 [ЭАектронный ресурс]. Аоступ из СПС «КонсультантПиюс»).

В настоящее время отмечается некоторое видоизменение схем хищения денежных средств в системах Аистанционного банковского об- 
служивания ( $А Б О)$. ЗАоумышленники аАаптировались к возрастающему уровню безопасности банковских систем.

Например, российскими кредитными организациями в 2017 г. утверждены принципы «двухфакторной авторизации», предполагающей проведение операции по двум независимым каналам (аккаунт $А Б О$, звонок по телефону, СМС-подтверждение, код со скретч-карты или чека, электронная подпись и др.). В ответ на эти меры представители российских ОПС начаци использовать методы замены сим-карт мегальных владельцев банковских счетов. Ранее указанные действия были характерны дмя мелкого мошенничества, однако в текушем году объектами преступных посягательств стали главные бухгалтеры и руководители крупных коммерческих предприятий. Объем похищенных денежных среАств в таких случаях исчисляется мимлионами рублей.

В заключение отметим, что противодействие использованию информационных сетей преступными группами, специализирующимися на вымогательствах, мошенничествах и кражах, совершении преступлений в сфере компьютерной информации, а также защита важнейших информационных инфраструктур от кибератак имеют ключевое значение Аля внешней и внутренней безопасности как отдемьно взятых государств, так и стран СНГ в целом [5]

Решение этой задачи предполагает совместную работу правоохранительных и иных государственных органов, выстраивание взаимодействия и обмена информацией на национальном и межгосударственном уровне, а также выработку и реализацию комплекса нормативно-правовых и организационных мер по противодействию деятельности террористических и иных преступных организаций и сообществ.

\section{Библиографический список}

1. Кузнеиов А.Г. Криминальные риски использования блокчейн-технологий и криптовалюты на территории государств - участников СНГ // Вестник Поволжского института управления. 2021. Т. 21, № 1. С. 48-55.

2. Давыдова Б.Д. Преступление в сфере информационных технологий // Проблемы совершенствования законодательства: сборник научных статей студентов юридического факультета. Махачкала, 2020. С. 89-91.

3. Материалы заседания коллегии МВД России от 1 нояб. 2019 г. URL: https://мвд. pф/news/item/18808269/

4. Лямцев А.Н. Мобильные коммуникационные устройства и их использование в противоправных целях // Вопросы современной науки и практики / Университет им. В.И. Вернадского. 2014. № 4(54). С. 200-204.

5. Аналитический обзор: Новые способы совершения преступлений в сфере информационных технологий на территории государств - участников СНГ в 2017 г. / И.Б. Колчевский, В.М. Журавлев, А.Г. Кузнецов [и др.]. М., 2017. 